\title{
Diabetes, hypertension and mobility among Brazilian older adults: findings from the Brazilian National Household Sample Survey (1998, 2003 and 2008)
}

Clarissa de Matos Nascimento', Juliana Vaz de Melo Mambrini', Cesar Messias de Oliveira², Karla Cristina Giacomin ${ }^{1,3}$ and Sérgio Viana Peixoto ${ }^{1,4^{*}}$

\begin{abstract}
Background: The rapid population ageing has been accompanied by a growing number of older adults experiencing chronic conditions, especially diabetes and hypertension, which are conditions associated to the decline in physical functioning. The aim of this study was to investigate changes in the strength of the association between mobility and two chronic conditions (hypertension and diabetes) in a large representative sample of Brazilian older adults over a ten year period.

Methods: The data came from the Brazilian National Household Sample Survey (PNAD) of 1998, 2003 and 2008. The sample comprised 28,943 participants aged 60 years and older investigated in 1998, 35,042 in 2003 and 41,269 in 2008, totalling 105,254 older adults. The dependent variable was the physical mobility index (PMI) constructed based on the Item Response Theory (IRT) using five physical mobility indicators. The chronic conditions were self-reported and the confounders included: age, sex, schooling, ethnicity, family income, household composition, other co-morbidities and use of health services. The association between physical mobility (three different groups) and chronic conditions (hypertension and diabetes) was performed using multinomial logistic regression.

Results: Over the ten year period the prevalence of hypertension increased from $44 \%$ (1998), $49 \%$ (2003) to $53 \%$ (2008) $(p<0.001)$. Similar pattern was observed for the prevalence of diabetes: $10 \%$ in 1998, $13 \%$ in 2003 and $16 \%$ in $2008(p<0.001)$. Overall, physical mobility showed a statistical significant association with both chronic diseases studied even after adjusting for potential confounders. The time-disease interaction term was significant $(p<0.05)$ for the two chronic conditions studied, and the strength of the associations decreased over the first five years, but it was not sustained between 2003 and 2008.

Conclusions: Despite the increases observed in the prevalence of the hypertension and diabetes over the ten year period, the decrease in strength of the association with physical mobility during the first period could be explained by improvements in health services and treatment of older adults. Special attention should be given to the treatment and management of diabetes in order to avoid declines in physical mobility levels.
\end{abstract}

Keywords: Hypertension, Diabetes, Mobility, Older adults, Item response theory

\footnotetext{
* Correspondence: sergio@cpqrr.fiocruz.br

${ }^{1}$ Rene Rachou Research Center, Oswaldo Cruz Foundation, Belo Horizonte,

Minas Gerais, Brazil

${ }^{4}$ Nursing School, Federal University of Minas Gerais, Belo Horizonte, Minas

Gerais, Brazil

Full list of author information is available at the end of the article
} 


\section{Background}

The preservation of the capacity to live independently and to function well during later life is important from both individual quality of life and public health perspectives. Mobility is a critical characteristic for functioning independently [1]. Those who lose mobility have higher rates of morbidity, hospitalization, disability, institutionalization and mortality. They also have a higher probability of developing depression and social isolation [2].

In addition to the basic activities of daily living (ADLs) and the instrumental activities of daily living (IADLs), physical functioning among older adults can be assessed by mobility level. The level of mobility can be measured by a self-reported scale starting with simple tasks like the ability to move from a bed to a chair to more physically challenging tasks such as short and long walks as well as climbing stairs [3]. Mobility is a very important indicator when investigating the relationship between physical functioning and sociodemographics, chronic conditions and health behaviours [4].

The Brazilian population is undergoing one of the fastest ageing processes worldwide. Ageing has consequently become more important for social policy development $[5,6]$. In addition, there has been an increase in the proportion of older adults in Brazil presenting with multiple chronic disease, especially diabetes and hypertension, which are conditions associated to the decline in physical functioning [7, 8]. Hypertensive individuals have greater risk of developing physical functioning difficulties, dementia, depression and falls [7]. In addition, hypertension has an independent association with a decline in physical mobility $[7,9,10]$. Diabetes is a chronic disease with multiple causes [11] and recent studies have demonstrated that diabetic older adults show greater loss in mobility when compared to non-diabetic individuals $[8,12]$.

In Brazil, approximately half of the men and more than half of women aged 60 years and over reported previous diagnosis of hypertension, and the control of the disease $(<140 / 90 \mathrm{~mm} \mathrm{Hg})$ is unsatisfactory [13]. The prevalence of diabetes also increase exponentially with age, from $0.5 \%$ in those $18-24$ years old to $21.4 \%$ in those 65 years or older [14]. Primary care services have grown rapidly in Brazil since 1994, with the implementation of Family Health Program, leading to a reduction in rates of hospitalizations for many ambulatory care-sensitive chronic diseases, but this trend was not observed for hypertension (among male) and diabetes [15]. Considering this context, it is important to access the impact of these chronic conditions on the health of the elderly, especially with regard to physical functioning, which is directly linked to quality of life and successful ageing.

Therefore, the aim of this study was to investigate changes in the strength of the association between mobility and two chronic conditions (i.e. diabetes and hypertension) among Brazilian older adults between 1998 and 2008.

\section{Methods}

\section{Study sample}

The data came from the Brazilian National Household Sample Survey (PNAD) of 1998, 2003 and 2008. PNAD is a nationally representative survey conducted by the Brazilian Institute of Geography and Statistics (IBGE), that recruits participants using a three-stage complex probabilistic household sample and is representative of the national and regional levels. In the first stage municipalities are selected and divided in self-representative, with probability $100 \%$ of belonging to the sample and non-representative which probability of belonging to the sample is proportional to the resident population. In the second stage, census tract are selected, which the probability of participation is proportional to the number of household in the tract. In the third stage, household are sampled in each census tract and the information relating to all household resident are collected through interview [16-18].

The sample comprised 28,943 participants aged 60 years and older investigated in 1998, 35,042 in 2003 and 41,269 in 2008, totalling 105,254 older adults eligible. The participants with information for all study variables considered for this analysis were 27,711 in 1998, 33,797 in 2003 and 39,500 in 2008. Thus, our final analytical sample comprised 101,008 older adults.

\section{Measures}

\section{Physical mobility}

The dependent variable was the physical mobility index (PMI) based on Item Response Theory (IRT) [19] using the following mobility items: "Normally, because of a health problem, do you have difficulty in": 1. Running, lifting weight, doing sports or doing heavy work?; 2. Pushing a table or doing a home repair?; 3. Going up a steep hill or stairs?; 4. Stooping or kneeling?; 5. Walking about $100 \mathrm{~m}$ ? Possible response options to each item were: unable to do it; great difficulty; small difficulty and no difficulty at all. The internal consistency of the index based on the five physical mobility items mentioned above was tested using the Cronbach's Alpha $(\alpha=0.915)$. More detailed information regarding the IRT can be found elsewhere [19-21].

IRT scores were categorized into three groups due the asymmetric distribution of the score, with $27.2 \%$ of the older adults without difficulty to perform the activities considered, and thus classified as group 1. The other two groups were defined based on the median score, excluding the individuals from the first group. As the value of the score represents the degree of difficulty in activities, the use of the median value could differentiate the 
group of respondents with some difficulty among those with moderate and great difficulty. Therefore, older adults were classified according to their level of difficulty to perform the five physical mobility items as follows: group 1 = no difficulty; group $2=$ moderate difficulty and group 3 = great difficulty.

\section{Diabetes and hypertension}

Self-reported diagnosed diabetes and hypertension were the chronic diseases used in the analyses.

\section{Covariates}

We included age (60-69 years, 70-79 years and 80 and over), sex, years of schooling (none, between 1 and 3, 4 and over), ethnicity (white, non-white), and household composition (live alone, live with other people). The per capita family income was obtained from the income total household divided by the number of residents. Per capita family income were converted into Brazilian monthly minimum wages $(1998=$ US\$ 110.17; $2003=$ US\$ 80.54 and $2008=$ US\$ 253.05) and grouped in tertiles. A variable called number of self-reported co-morbidities (none, 1 or more) was constructed based on the following question: "Have you ever been diagnosed by a medical doctor with the following health condition?" back problems, arthritis, cancer, diabetes, bronchitis or asthma, hypertension, heart disease, chronic kidney disease, depression, tuberculosis, tendinitis and cirrhosis. The use of health services was measured by both the number of medical consultations and hospitalization in the past 12 months. These potential confounders were chosen based in the literature [2, 9, 22, 23].

\section{Statistical analyses}

The physical mobility index was constructed using the Itm (latent trait model) package [24] from $\mathrm{R}$ software [25]. The other analyses were conducted using STATA version 13 (College Station, Texas, USA) for complex surveys design, considering the survey weights and the effect of sampling design [26]. The association between explanatory variables and survey years (1998, 2003 and 2008) were measure by Pearson's chi-square test. Multinomial logistic regression was used to estimate the odds ratio, and their $95 \%$ confidence intervals, of having physical mobility difficulties in relation to the presence of diabetes and hypertension, for each year. Group no difficulty was the reference category. The generalised Hosmer-Lemeshow test was used to assess the fitness of the models. The trends in the associations were evaluated by the year-disease interaction term in all models. The level of significance was $5 \%$.

\section{Results}

Table 1 shows sample characteristics over the ten year period (i.e. 1998-2008). Overall, we found that there was a significant increase in the proportion of the oldest old group, those with 4 or more years of education, nonwhite, in the second tertile of family income and those living alone. Despite a reduction in the prevalence of one or more self-reported chronic conditions, the prevalence of hypertension increased from $44.1 \%$ (1998), to $49.0 \%(2003)$ and then to $53.4 \%(2008)(p<0.001)$. A similar pattern was observed for the prevalence of diabetes from $10.3 \%$ (1998), to $13.0 \%$ (2003) and then to $16 \%(2008)(p<0.001)$. In addition, it was observed the increase of the number of physician visits and the reduction of hospitalizations over the ten year period.

The physical mobility indicators measured in this study are described in Table 2 . There was a significant association between year of survey and all the mobility tasks considered. The Physical Mobility Index showed an increase in the group without difficult and a decrease of the proportion in the moderate difficult group, over the period considered.

The results of the multinomial logistic regression examining the association between the index of physical mobility, hypertension and diabetes are given in Table 3. Considering the adjusted model, respondents in the moderate difficulty group showed a discrete reduction in the strength of the association between both chronic diseases and physical mobility, but this trend was not significant ( $p>0.05$ for this category). On the other hand, the group with great difficulty to perform mobility activities showed a reduction in the strength of the association from 1998 to $2003(p<0.05)$, but this trend was not sustained in the last five years.

\section{Discussion}

The main findings from the present study showed a significant association between physical mobility and two chronic conditions (hypertension and diabetes) in three nationally representative sample of Brazilian older adults. In addition, despite an increase in the prevalence of hypertension and diabetes from 1998 to 2008, the magnitude of the association between these chronic conditions and physical mobility did not change among those in the moderate difficulty group. However, among those with great difficulty, there was a decrease in the magnitude of these associations from 1998 to 2003, but our findings showed no change in the magnitude of the association for hypertension and a small increase in the strength of the association for diabetes, between 2003 and 2008.

The increase in prevalence of diabetes and hypertension among older adults in Brazil is similar to those observed in the USA [27] and Holland [22] in the same age group. Among American older adults data came 
Table 1 Socio-demographic characteristics, health status and use of health services among Brazilian older adults (PNAD - 1998, 2003 and 2008)

\begin{tabular}{|c|c|c|c|c|}
\hline \multirow[t]{2}{*}{ Variable } & \multicolumn{4}{|l|}{ Year } \\
\hline & $1998(\%)$ & $2003(\%)$ & $2008(\%)$ & $p$-value \\
\hline Gender: Female & 55.6 & 56.0 & 56.1 & 0.274 \\
\hline \multicolumn{5}{|l|}{ Age (years) } \\
\hline $60-69$ & 57.3 & 55.5 & 55.4 & \multirow[t]{3}{*}{$<0.001$} \\
\hline 70-79 & 30.7 & 32.1 & 31.0 & \\
\hline $80+$ & 12.0 & 12.3 & 13.5 & \\
\hline \multicolumn{5}{|l|}{ Schooling (years) } \\
\hline Illiterate & 41.5 & 37.2 & 32.8 & \multirow[t]{3}{*}{$<0.001$} \\
\hline 1 to 3 & 22.2 & 21.2 & 19.7 & \\
\hline 4 or more & 36.7 & 41.6 & 47.5 & \\
\hline Self-declared skin colour: white & 61.0 & 59.2 & 55.6 & $<0.001$ \\
\hline \multicolumn{5}{|c|}{ Family Income in Brazilian minimum wages (tertile) } \\
\hline First & 42.1 & 45.3 & 43.5 & \multirow[t]{3}{*}{$<0.001$} \\
\hline Second & 19.6 & 21.5 & 24.2 & \\
\hline Third & 38.8 & 33.1 & 32.1 & \\
\hline $\begin{array}{l}\text { Household Composition: live } \\
\text { alone }\end{array}$ & 11.9 & 13.0 & 14.0 & $<0.001$ \\
\hline Diabetes & 10.3 & 13.0 & 16.0 & $<0.001$ \\
\hline Hypertension & 44.1 & 49.0 & 53.4 & $<0.001$ \\
\hline $\begin{array}{l}\text { One or more self-reported } \\
\text { chronic disease }^{a}\end{array}$ & 69.2 & 60.3 & 58.2 & $<0.001$ \\
\hline \multicolumn{5}{|c|}{ Number of physician visits in the last 12 months } \\
\hline None & 27.8 & 21.8 & 18.7 & \multirow[t]{3}{*}{$<0.001$} \\
\hline $1-3$ & 39.1 & 38.3 & 39.4 & \\
\hline 4 or more & 33.1 & 39.8 & 41.9 & \\
\hline $\begin{array}{l}\text { One or more hospitalizations in } \\
\text { the last } 12 \text { months }\end{array}$ & 13.7 & 12.7 & 12.3 & $<0.001$ \\
\hline
\end{tabular}

Note: $p$-values were derived from chi-square tests. ${ }^{a}$ Chronic disease: back problems, arthritis, cancer, diabetes, bronchitis or asthma, hypertension, heart disease, chronic kidney disease, depression, tuberculosis, tendinitis and cirrhosis

from two national surveys namely the Health and Retirement Study (HRS) and the Asset and Health Dynamics (AHEAD) from years 1998, 2004 and 2008, showing an increase in the prevalence of these two chronic conditions [27]. Similar findings were reported from a prospective Dutch study between 1992 and 2009 [22]. This increase observed in Brazil and other countries could be partly attributed to the implementation of new diagnostic criteria, improvements in treatments and more access to health care, leading to a better management of these two chronic diseases and, consequently, less healthrelated complications such as disability [27].

Overall, more than $20 \%$ of the respondents did not report any difficulty to perform any of the five mobility tasks according to the physical mobility index (PMI) used in this study. The literature on changes over time
Table 2 Physical mobility indicators among Brazilian older adults (PNAD - 1998, 2003 and 2008)

\begin{tabular}{|c|c|c|c|c|}
\hline \multirow{2}{*}{$\begin{array}{l}\text { Mobility tasks/level } \\
\text { of difficulty }\end{array}$} & \multicolumn{3}{|l|}{ Year } & \multirow[b]{2}{*}{$p$-value } \\
\hline & $1998(\%)$ & $2003(\%)$ & $2008(\%)$ & \\
\hline \multicolumn{5}{|c|}{ Running, lifting heavy objects, playing sports or doing heavy work } \\
\hline None & 30.6 & 34.8 & 34.3 & \multirow[t]{4}{*}{$<0.001$} \\
\hline Little & 22.8 & 21.0 & 21.4 & \\
\hline Great & 25.1 & 23.6 & 23.0 & \\
\hline Can not & 21.5 & 20.6 & 21.2 & \\
\hline \multicolumn{5}{|c|}{ Pushing a table or doing a home repair } \\
\hline None & 55.4 & 58.5 & 52.7 & \multirow[t]{4}{*}{$<0.001$} \\
\hline Little & 22.7 & 20.0 & 21.8 & \\
\hline Great & 11.0 & 10.5 & 12.9 & \\
\hline Can not & 11.0 & 11.0 & 12.6 & \\
\hline \multicolumn{5}{|c|}{ Going up a steep hill or stairs } \\
\hline None & 40.4 & 45.5 & 45.1 & \multirow[t]{4}{*}{$<0.001$} \\
\hline Little & 25.6 & 22.6 & 23.4 & \\
\hline Great & 21.5 & 19.2 & 18.9 & \\
\hline Can not & 12.5 & 12.6 & 12.5 & \\
\hline \multicolumn{5}{|l|}{ Stooping or Kneeling } \\
\hline None & 44.7 & 48.7 & 45.8 & \multirow[t]{4}{*}{$<0.001$} \\
\hline Little & 25.7 & 22.6 & 24.1 & \\
\hline Great & 18.7 & 17.3 & 18.7 & \\
\hline Can not & 11.0 & 11.3 & 11.4 & \\
\hline \multicolumn{5}{|l|}{ Walking about $100 \mathrm{~m}$} \\
\hline None & 74.8 & 77.3 & 72.0 & \multirow[t]{4}{*}{$<0.001$} \\
\hline Little & 12.4 & 10.5 & 14.3 & \\
\hline Great & 4.9 & 4.6 & 5.6 & \\
\hline Can not & 7.8 & 7.6 & 8.1 & \\
\hline \multicolumn{5}{|c|}{ Physical Mobility Index } \\
\hline No difficulty & 24.6 & 28.0 & 28.5 & \multirow[t]{3}{*}{$<0.001$} \\
\hline Moderate difficulty & 38.7 & 37.4 & 35.2 & \\
\hline Greater difficulty & 36.7 & 34.6 & 36.3 & \\
\hline
\end{tabular}

Note: $p$-values were derived from chi-square tests

in the prevalence of indicators of mobility shows inconsistencies. In the USA, a reduction was observed in the physical mobility decline among older adults (aged 65 and over) between 1982 and 1994 [28] and also among those aged 70 and over between 1982 and 2005 [29]. On the other hand, data from the American people aged 65 and over between 2000 and 2005 showed an increase in the prevalence of physical mobility difficulties [30]. Similar findings were reported from a study conducted in Singapore among residents aged 55 and over (1995-2005) [1]. Such differences in the prevalence changes of indicators of physical mobility over time could be due to differences in sample designs, measures used and analytical approaches as well as changes in the health conditions over time [1]. 
Table 3 Results of the multinomial logistic regression analyses examining the association between physical mobility, hypertension and diabetes in a representative sample of Brazilian older adults (PNAD - 1998, 2003 and 2008)

\begin{tabular}{|c|c|c|c|c|c|c|}
\hline \multirow[t]{3}{*}{ Disease/Mobility } & \multirow{2}{*}{\multicolumn{2}{|c|}{$\begin{array}{l}1998 \\
\text { OR (95 \% Cl) }\end{array}$}} & \multirow{2}{*}{\multicolumn{2}{|c|}{$\begin{array}{l}2003 \\
\text { OR (95 \% Cl) }\end{array}$}} & \multirow{2}{*}{\multicolumn{2}{|c|}{$\begin{array}{l}2008 \\
\text { OR (95 \% Cl) }\end{array}$}} \\
\hline & & & & & & \\
\hline & Model 1 & Model 2 & Model 1 & Model 2 & Model 1 & Model 2 \\
\hline \multicolumn{7}{|l|}{ Hypertension } \\
\hline No difficulty & 1.00 & 1.00 & 1.00 & 1.00 & 1.00 & 1.00 \\
\hline Moderate difficulty & $2.15(1.99-2.34)$ & $1.51(1.39-1.65)$ & $2.07(1.93-2.21)$ & $1.44(1.34-1.56)$ & $1.89(1.77-2.01)$ & $1.37(1.28-1.46)$ \\
\hline Great difficulty & 3.89 (3.60-4.21) & $2.01(1.83-2.21)$ & $3.45(3.22-3.70)$ & $1.75(1.61-1.90)$ & $3.28(3.08-3.49)$ & $1.76(1.64-1.89)$ \\
\hline \multicolumn{7}{|l|}{ Diabetes } \\
\hline No difficulty & 1.00 & 1.00 & 1.00 & 1.00 & 1.00 & 1.00 \\
\hline Moderate difficulty & $1.90(1.63-2.21)$ & $1.44(1.23-1.69)$ & $1.67(1.50-1.88)$ & $1.19(1.05-1.35)$ & $1.57(1.43-1.72)$ & $1.21(1.10-1.33)$ \\
\hline Great difficulty & $3.43(2.97-3.97)$ & 2.07 (1.75-2.44) & $2.88(2.59-3.20)$ & $1.56(1.37-1.77)$ & $2.82(2.58-3.08)$ & $1.80(1.62-2.00)$ \\
\hline
\end{tabular}

OR (95\% Cl): odds ratio (confidence interval at $95 \%$ ). Model 1 adjusted for time-disease interaction term. Model 2 adjusted for time-disease interaction term, sex, age, education, race, family components, income, number of diseases (except hypertension for hypertension model and except diabetes for diabetes model), number of physician visits, hospitalization

These highlight the difficulty in establishing a general pattern of change in physical mobility among older adults from different populations.

The findings showed a significant association between hypertension and worsening physical mobility. Studies that assessed mobility using objective physical measurements also found an association with hypertension, which corroborate our findings [9, 10]. An American prospective study between 1989 and 2007 conducted with 643 older adults showed that higher systolic blood pressure was associated with a rapid decline in walking speed [9]. Data from a Swedish study conducted between 2001 and 2004 in 2725 older adults aged 60 and over also showed an association between cardiovascular diseases (including hypertension) and limitations in mobility, defined as walking speeding. They also reported that those respondents with two or more cardiovascular diseases were three times more likely to have mobility difficulties [10]. The hypertension has silent symptoms but when uncontrolled, it can lead to the evident symptom, which increases the probability of a decline in physical mobility [31]. The possible explanation for this association is through its effect on white matter hyperintensities in the brain, cerebrovascular function, overall lean muscle mass, inflammation or changes in the renin angiotensin system [31]. White matter hyperintensities are closely related to hypertension and have been connected with mobility impairment [7]. This could be a potential explanation for the association between hypertension and decline in physical mobility.

Similarly in relation to hypertension, there was a significant association between physical mobility status and diabetes in the present study. A prospective study, conducted in Spain between 2000 and 2007 in older adults aged 65 and over, showed a significant association between diabetes and mobility difficulties assessed by self- reported difficulty to walk for an hour without resting and climbing ten steps [8]. Similar findings were observed in a Mexican population of older adults living in the USA followed up for seven years (1993-2001). Mobility was measured by questions about difficulties to climb steps and walking half a mile [32]. Studies that assessed mobility using objective physical tests also reported a significant association with diabetes [12, 33] illustrating the importance of diabetes in the decline of physical mobility. In a cross-sectional study conducted among Italian older adults enrolled in the inCHIANTI (Invecchiare in Chianti, aging in the Chianti area) the mobility was assessed by $4 \mathrm{~m}$ and $400 \mathrm{~m}$ walking speed, and the diabetics participants were significantly slower when compared to non-diabetics [33]. Another crosssectional study, in southern Netherlands, the authors evaluated the mobility by a 6 min walk test and timed up and go test, observed that diabetics had a decrease in mobility compared to the non-diabetics [12]. Therefore, it is crucial to detect diabetes in its early stage in order to avoid health-related complications that will lead to a decline in physical functioning [34].

Overall, our findings showed a decrease in the magnitude of changes in the associations among those with great difficulty, from 1998 to 2003, which was not observed between 2003 and 2008. A study from the USA reported similar findings to ours namely a reduction in the association between hypertension and the decline in mobility in the years 1998, 2004 and 2008. In addition, a reduction was found in the strength of the association between diabetes and mobility decline from 1998 to 2004 and an increase in the strength of the association in 2008. These findings corroborate ours and highlight the fact that chronic diseases are highly associated with disability. One should note the recent increase of the association between diabetes and difficulties in physical 
mobility [23]. Thus, studies looking into changes in the strength of the association between chronic conditions and physical functioning over time are essential to provide information about the impact of such diseases on levels of physical mobility among older adults and, consequently, helping health services to prioritize the best interventions [23, 32].

In order to minimise the health-related complications caused by diabetes and hypertension, the Brazilian Ministry of Health implemented a series of public health interventions at a primary care level in 2002. One of them is the free and continuous distribution of medication for the treatment of diabetes and hypertension as well as the monitoring of clinical aspects of patients with such conditions using the free Brazilian national health service (SUS) [35, 36]. However, there is a need to further increase such intervention in order to reduce the impact of both diabetes and hypertension on physical mobility decline found in the present study. Another concern is the reduction in the quality of life of older adults around the world as a result of the increase in the magnitude of the association between diabetes and difficulties in physical mobility and the increase in the prevalence of diabetes [23, 32].

Our study has some limitations. Its cross-sectional nature does not allow establishing temporal causation, although the literature shows that both diabetes and hypertension are associated with a decline in physical mobility [7, 37]. Chronic disease was based on selfreport of physician diagnosis, though previous work has demonstrated the validity of this measure especially among older adults [32, 38, 39]. The medication compliance variable is not available from the primary dataset. This variable is important for assessing association between chronic disease and mobility, because the use of medication can help to attenuate, prevent or retard disability [31]. Finally, in 1998, the self-reported diagnosed question was different from the one used in years 2003 and 2008. This change should however is not likely to alter the estimates of prevalence of the chronic conditions as discussed in a previous study [40]. On the other hand, it is important to highlight that the sample used in this analysis is nationally representative of the Brazilian older adult population from all geographic regions. PNAD collects important data to assess the potential impacts of policies implemented by the Brazilian government to improve both the health and socioeconomic conditions of the Brazilian population [41]. Another strength of this study is the use of a score that summarises five physical mobility indicators based on the Item Response Theory (IRT). Very few studies have used the IRT to investigate physical functioning [42-44]. This approach generates a scale that allows differentiation of respondents according to their different levels of physical mobility taking into account various questions that measure this domain [44].

\section{Conclusions}

In summary, this study revealed that among Brazilian older adults there was an increase in the prevalence of both hypertension and diabetes from 1998 to 2008. Our findings also showed that there was a trend of reduction in the strength of the association between these two chronic conditions and great difficulty in physical mobility in the first five years, indicating a relative improvement in public health policies to better manage these chronic conditions in Brazil, but this trend was not observed between 2003 and 2008. Nevertheless, this study was able to demonstrate that diabetes, hypertension and physical mobility are important issues for older adults in Brazil and that their relationship is an area that needs to be researched further in order to improve our understanding of the mechanisms through which they impact upon the individual and society. This in turn would enable the development of appropriate policies and target interventions effectively to prevent declines in physical mobility. The fact that both chronic diseases studied have been shown to affect a high proportion of individuals in later life is relevant to public policy.

\section{Abbreviations \\ ADL: Activities of daily living; IADL: Instrumental activities of daily living; PNAD: National Household Sample Survey; IBGE: Brazilian Institute of Geography and Statistics; PMI: Physical mobility index; TRI: Item Response Theory; HRS: Health and Retirement Study; AHEAD: Asset and Health Dynamics.}

\section{Competing interests}

The authors declare that they have no competing interests.

\section{Authors' contribution}

CMN collaborated in conception and design of the study, acquisition of data, analysis and interpretation of data, reviewed literature and wrote the manuscript. JVMM collaborated in the analysis and interpretation of data. CMDO collaborated commented on the text and helped in the review. KG collaborated commented on the text and helped in the review. SVP collaborated in the conception and design of the study, analysis and commented on the text. All the authors reviewed and approved the final manuscript.

\section{Acknowledgments}

The authors thank Centro de Pesquisas René Rachou (CPqRR-Fiocruz Minas). CMN thanks CAPES (Coordenação de Aperfeiçoamento de Pessoal de Nível Superior, 12099-13-9 process) by schorlaship study. SVP is researcher productivity scholar of Conselho Nacional de Desenvolvimento Científico e Tecnológico (CNPq).

\section{Author details}

${ }^{1}$ Rene Rachou Research Center, Oswaldo Cruz Foundation, Belo Horizonte, Minas Gerais, Brazil. ${ }^{2}$ Research Department of Epidemiology and Public Health, University College London, London, UK. ${ }^{3}$ Secretaria Municipal de Saúde de Belo Horizonte, Belo Horizonte, Minas Gerais, Brazil. ${ }^{4}$ Nursing School, Federal University of Minas Gerais, Belo Horizonte, Minas Gerais, Brazil.

Received: 20 March 2015 Accepted: 19 June 2015

Published online: 27 June 2015 


\section{References}

1. Yong V, Saito $Y$, Chan A. Changes in the prevalence of mobility limitations and mobile life expectancy of older adults in Singapore, 1995-2005. J Aging Health. 2010:22(1):120-40.

2. Gill TM, Gahbauer EA, Murphy TE, et al. Risk factors and precipitants of long-term disability in community mobility: A cohort study of older persons. Ann Inter Med. 2012;156(2):131-40.

3. Guralnik JM, Fried LP, Salive ME. Disability as a public health outcome in the aging population. Annu Rev Public Health. 1996;17:25-46.

4. Ramos LR. Determinant factors for healthy aging among senior citizens in large city: The Epidoso Project in São Paulo. Cad Saude Publica. 2003;19(3):793-8.

5. Lima-Costa MF, Veras R. Saúde pública e envelhecimento. Cad Saude Publica. 2003;19(3):700-1.

6. Veras R. Fórum: Envelhecimento populacional e as informações de saúde do PNAD: demandas e desafios contemporâneos. Introdução Cad Saude Publica. 2007;23(10):2463-6.

7. Hajjar I, Quach L, Yang F. Hypertension, white matter hyperintensities, and concurrent impairments in mobility, cognition, and mood: The Cardiovascular Health Study. Circulation. 2011;123:858-65

8. Martinez-Huedo MA, Andres AL, Hernandez-Barrera V, et al. Trends in the prevalence of physical and functional disability among Spanish elderly suffering from diabetes (2000-2007). Diabetes Res Clin Pract. 2011;94:30-3.

9. Rosano C, Longstreth Junior WT, Boudreau R, et al. High blood pressure accelerates gait slowing in well-functioning older adults over 18-Years of follow-up. J Am Geriatr Soc. 2011;59(3):390-7.

10. Welmer AK, Angleman S, Rydwik E, et al. Association of cardiovascular burden with mobility limitation among elderly people: a population-based study. PLoS One. 2013;8(5):1-7.

11. Bruce DG, Davis WA, Davis TME. Longitudinal predictors of reduced mobility and physical disability in patients with type 2 diabetes. Diabetes Care. 2005:28:2441-7.

12. ljzerman TH, Schaper NC, Melai T, Meijer K, Willems PJ, Savelberg HH. Lower extremity muscle strength is reduced in people with type 2 diabetes, with and without polyneuropathy, and is associated with impaired mobility and reduced quality of life. Diabetes Res Clin Pract. 2012;95:345-51.

13. Schmidt MI, Duncan BB, Azevedo e Silva G, Menezes AM, Monteiro CA Barreto SM, et al. Chronic non-communicable disease s in Brazil: burden and current challenges. Lancet. 2011;377(9781):1949-61.

14. Iser BPM, Malta DC, Duncan BB, Moura L, Vigo A, Schmidt MI. Prevalence, correlates, and description of self-reported diabetes in Brazilian capitals - results from a telephone survey. PLoS One. 2014;9(9):e108044.

15. Macinko J, Dourado I, Aquino R, Bonolo PF, et al. Major expansion of primary care in Brazil linked to decline in unnecessary hospitalization. Health Aff. 2010;29(12):2149-60.

16. IBGE. Instituto Brasileiro de Geografia e Estatística. Pesquisa Nacional por Amostra de Domicílios. Acesso e Utilização de Serviços de Saúde: 1998. Rio de Janeiro: IBGE; 2000. http://www.ibge.gov.br/home/estatistica/populacao/ trabalhoerendimento/pnad98/saude/saude.pdf. Accessed 18 nov 2014.

17. IBGE. Instituto Brasileiro de Geografia e Estatística. Pesquisa Nacional por Amostra de Domicílios. Síntese de Indicadores Sociais 2003. Rio de Janeiro: IBGE; 2004. http://www.ibge.gov.br/home/estatistica/populacao/ condicaodevida/indicadoresminimos/sinteseindicsociais2003/ indic_sociais2003.pdf. Accessed 18 nov 2014.

18. IBGE. Instituto Brasileiro de Geografia e Estatística. Pesquisa Nacional por Amostra de Domicílios - um panorama da saúde no Brasil: acesso e utilização dos serviços, condições de saúde e fatores de risco e proteção à saúde 2008. Rio de Janeiro: IBGE; 2010. http://bvsms.saude.gov.br/bvs/ publicacoes/pnad_panorama_saude_brasil.pdf. Accessed 18 nov 2014

19. Samejina FA. Estimation of latente ability using $s$ response pattern of graded scores. Psychometric Monograph. lowa: Psichometric Society. 1969;17.

20. Hays RD, Liu H, Spritzer K, et al. Item response theory analyses of physical functioning items in the medical outcomes study. Med Care. 2007;45(s.1):32-8.

21. Moreira Junior FJ. Aplicações da teoria de resposta ao item (TRI) no Brasil. Revista Brasileira de Biometria. 2010;28(4):137-70.

22. Galenkamp H, Braam AW, Huisman M, et al. Seventeen-year time trend in poor self-rated health in older adults: changing contributions of chronic diseases and disability. Eur J Public Health. 2012:23(3):511-7.
23. Hung WW, Ross JS, Boockvar KS, et al. Association of chronic diseases and impairments with disability in older adults: a decade of change? Med Care 2012;50(6):501-7

24. Rizopoulos D. Itm: an R package for latent variable modelling and item response theory analyses. J Stat Softw. 2006;17(5):1-25.

25. R Core Team. R: A language and environment for statistical computing. Foundation for Statistical Computing, Vienna, Austria. 2013. ISBN 3-900051-07-0. http://www.R-project.org/. Accessed 10 nov 2014.

26. Silva PLN, Pessoa DGC, Lila MF. Análise estatística de dados da PNAD: incorporando a estrutura do plano amostral. Cien Saude Colet. 2002;7(4):659-70.

27. Hung WW, Ross JS, Boockvar KS, et al. Recent trends in chronic disease, impairment and disability among older adults in the United States. BMC Geriatr. 2011:11(47):1-12.

28. Wolf DA, Leon CFM, Glass TA. Trends in rates of onset of and recovery from disability at older ages: 1982-1994. J Gerontol B Psychol Sci Soc Sci. 2007;62B(1):3-10.

29. Schoeni RF, Freedman VA, Martin LG. Why is late-life disability declining? Milbank Q. 2008;86:47-89.

30. Fuller-Thomson BY, Nuru-Jeter A, Guralnik JM, et al. Basic ADL disability and functional limitation rates among older americans from 2000-2005: The end of the decline? J Gerontol A Biol Sci Med Sci. 2009;64(12):1333-6.

31. Haijar I, Lackland D, Cupples LA, Lipsitz LA. The association between concurren and remote blood pressure and disability in older adults. Hypertension. 2007:50(6):1026-32.

32. Al Snih S, Fisher MN, Raji MA, et al. Diabetes mellitus and incidence of lower body disability among older Mexican Americans. J Gerontol A Biol Sci Med Sci. 2005;60(9):1152-6.

33. Volpato S, Bianchi L, Lauretani $F$, et al. Role of muscle mass and muscle quality in the association between diabetes and gait speed. Diabetes Care. 2012;35:1672-9.

34. Figaro MK, Kritchevsky SB, Resnick HE, et al. Diabetes, inflammation, and functional decline in older adults: findings from the health, aging and body composition (ABC) study. Diabetes Care. 2006:29(9):2039-45.

35. Santos JC, Moreira TMM. Fatores de risco e complicações em hipertensos/ diabéticos de uma regional sanitária do nordeste brasileiro. Rev Esc Enferm USP. 2012;46(5):1125-32.

36. Santos Pinto CB, Costa NR, Osorio-de-Castro CGS. Quem acessa o Programa Farmácia Popular do Brasil? Aspectos do fornecimento público de medicamentos. Cien Saude Colet. 2011;16(6):2963-73.

37. Stuck AE, Walthert JM, Nikolaus T, et al. Risk factors for functional status decline in community-living elderly people: a systematic literature review. Soc Sci Med. 1999:48(4):445-69.

38. Lima-Costa MFF, Peixoto SV, Firmo JOA. Validade da hipertensão arterial auto-referida e seus determinantes (projeto Bambuí). Rev Saude Publica. 2004;38(5):637-42.

39. Lima-Costa MF, Peixoto S, Firmo JOA, et al. Validade do diabetes autoreferido e seus determinantes: evidências do projeto Bambuí. Rev Saude Publica. 2007:41(6):947-53.

40. Lima- Costa MF, Matos DL, Camargos VP, et al. Tendências em dez anos das condições de saúde de idosos brasileiros: evidências da Pesquisa Nacional por Amostras de Domicílios (1998, 2003 e 2008). Cien Saude Coletiva. 2011;16(9):3689-96.

41. IBGE. Instituto Brasileiro de Geografia e Estatística. http://www.ibge.gov.br/ home/estatistica/populacao/trabalhoerendimento/pnad2012/ default_brasil.shtm. Accessed 10 set 2014.

42. Mambrini JVM. Desigualdade em saúde no Brasil: medida e avaliação [tese]. Belo Horizonte: Faculdade de Ciências Econômicas, Universidade Federal de Minas Gerais;2009.

43. Saliba D, Orlando M, Wenger NS, et al. Identifying a short functional disability screen for older persons. J Gerontol A Biol Sci Med Sci. 2000:55:750-6.

44. IBGE. Instituto Brasileiro de Geografia e Estatística. Textos para Discussão. Diretoria de Pesquisas número 45. Capacidade Funcional de Idosos. Uma análise dos Suplementos Saúde da PNAD com a teoria de resposta ao item. 2013. http://ebape.fgv.br/sites/ebape.fgv.br/files/estudo_capacidade_ funcional idosos kaizo beltrao.pdf. Accessed 13 nov 2014. 